PERSPECTIVAS

(artículos)

\title{
Las endechas judeoespañolas del norte de Marruecos, un análisis semiótico
}

FIGURAS REVISTA ACADÉMICA DE INVESTIGACIÓN

ISSN 2683-2917

Vol. 2, núm. 2, marzo-junio 2021

https://doi.org/10.22201/

fesa.figuras.2021.2.2

\section{(9)(1) $(0)$}

Esta obra está bajo una Licencia Creative Commons AtribuciónNoComercial-Compartirlgual 4.0 Internacional.

Recibido: 30 de junio de 2020

Revisado:

10 de agosto de 2020

Aceptado:

20 de noviembre de 2020 https://doi.org/10.22201/fesa.

figuras.2021.2.2.143

\section{The Judeo-Spanish Dirges in the Northern of Morocco: a Semiotic Analysis}

Norma Rosas-Mayén

University of Southern Indiana, Estados Unidos

Resumen: El objetivo del presente estudio es ofrecer un análisis semiótico de las endechas (cantos de muerte que fueron transmitidos de manera oral e intergeneracional entre las comunidades judías sefarditas que se asentaron en el norte de Marruecos después de su expulsión de España en 1492). El método utilizado en el presente trabajo es documental y está basado en la recopilación de endechas que realizó Manuel Alvar (1969) en las comunidades judeoespañolas de esta región, en la segunda mitad del siglo xx. En este estudio se concluye que el contenido semiótico de estos textos es relevante porque arroja luz sobre las costumbres y creencias mortuorias judeoespañolas medievales, y el papel que jugó la mujer judía sefardí como agente de transmisión de esta poética lúgubre en lengua haketía, hoy extinta.

Palabras clave: Endecha, semiosfera, semiosis, haketía, sefardita. 
Abstract: The aim of this study is to offer a semiotic analysis of the dirges (songs of the dead) that were transmitted orally and intergenerationally among the Sephardic Jewish communities that settled in northern Morocco after their expulsion from Spain in 1492. The method used in the present work is documental and is based on the compilation of dirges made by Manuel Alvar (1969) in the Judeo-Spanish communities of this region, in the second half of the 20th century. This study arrives to the conclusion that the semiotic content of these texts is significant, because it sheds light on medieval Judeo-Spanish mortuary customs and beliefs, as well as the role that Jewish Sephardic women played as agents of transmission of a lugubrious poetics in the Haketian language, nowadays extinct.

Keywords: Dirge, Semiosphere, Semiosis, Haketian, Sephardic.

\section{Introducción}

Después del Decreto de Expulsión de 1492, la comunidad judeoespañola que se exilió en el litoral norte de Marruecos conservó por casi cerca de cinco siglos no sólo su lengua, el judeoespañol - conocido localmente como haketía- ${ }^{1}$ sino también un rico bagaje cultural. No obstante, a raíz de la fundación del Estado de Israel (1948) y de la

1 De acuerdo con algunas fuentes (Bénichou 1945; Bendayan de Bendelac 1990; Jalfón de Bentolila 2011), el haketía -con ortografías vacilantes en haketilla, haquitía, jakitía, jaquetilla, haketiya, hakitiya - es la variedad lingüística del judeoespañol que se desarrolló en la región norte de Marruecos, conformada por variantes del castellano medieval del siglo XV con incrustaciones lingüísticas del hebreo y el árabe. Acerca de la lengua haketía, Ángeles Vicente nos comenta que: "En primer lugar, aludiremos a la variedad del español que llegó con los judíos expulsados de la Península Ibérica en 1492 y que se establecieron en el norte de Marruecos, especialmente en las ciudades de Tánger y Tetuán. Se trataba de una variedad de lengua romance, mezclada con rasgos del hebreo y del árabe, y conocida como hakitia, cuyo origen, según Benoliel (1977: 4), autor de la única descripción de esta lengua, es antiguo, ya que era hablada por los judíos en tierras hispanas antes de su expulsión, por lo que refleja algunas de las diferencias diatópicas entre los distintos romances hablados en la Península Ibérica. Una vez en el norte de África, su duración en el tiempo fue larga ya que los judíos mantuvieron su español arcaico hasta el siglo Xx, pues hablar esta lengua les proporcionaba cierta identidad y los diferenciaba de sus correligionarios autóctonos y hablantes de variedades judeo-árabes magrebíes. Cuando la hakitia desapareció, dejó hispanismos específicos sólo usados por parte de la población judía de Marruecos, por lo tanto, prácticamente caídos en desuso en la actualidad". (2011, 64) 
independencia de Marruecos (1956), la comunidad sefardita ${ }^{2}$ de esta región comenzó a decrecer drásticamente, poniendo su lengua y cultura en peligro de extinción. Aunado a ello, los cambios sociales, educativos y de costumbres que se suscitaron desde mediados del siglo xix y durante el xx tuvieron un impacto en la comunidad judeoespañola de esta región que aceleró el desvanecimiento, casi por completo, de sus elementos culturales y su función.

Entre los pocos remanentes culturales documentados que quedan de la comunidad judía sefardita del norte de Marruecos cabe destacar un interesante corpus de literatura oral, tanto en prosa (cuentos, refranes) como en verso (romances, canciones, coplas y endechas). Dentro de este repertorio, las endechas (cantos de muerte) llaman la atención por su singularidad y escasez, las cuales fueron recolectadas y dadas a conocer en la segunda mitad del siglo xx gracias al trabajo etnográfico de Manuel Alvar (1969) en esta zona geográfica.

En la actualidad, son contados los trabajos que se han enfocado en el estudio de estos cantos fúnebres judeoespañoles, entre ellos cabe mencionar los trabajos de Bénichou (1968) y de Díaz-Mas (1980; 1982; 2003; 2008). La presente investigación se suma a esta lista, a la par que ofrece un análisis semiótico de las endechas judeoespañolas marroquíes y está estructurado en cinco apartados. En el primer apartado, se define la endecha y el acto de endechar; en el segundo, aborda el aspecto teórico dentro del cual el presente estudio enmarca el análisis semiótico (semiosfera del texto) de las endechas judeoespañolas marroquíes; en el tercero, se presenta la estructura de la endecha; en el cuarto, se avoca al análisis semiótico de un seleccionado corpus de endechas; y, en el quinto, se exponen las conclusiones generales. Asimismo, se ofrece un pequeño glosario haketía-español con algunos de los términos encontrados en las endechas para una mejor comprensión de éstas.

2 El término sefardí, sefardita o sefaradita proviene de Sefarad, vocablo con el cual la Biblia designa a la península ibérica, como consta en el Libro de Abdías (1:20), en el que aparece por única vez la palabra Sefarad: "Y los cautivos de este ejército de los hijos de Israel poseerán lo de los cananeos hasta Sarepta, y los cautivos de Jerusalén que están en Sefarad poseerán las ciudades del Négueb". De acuerdo con Espinosa Villegas, el vocablo sefardí o sefardita ha sufrido una extensión semántica "para designar a todos aquellos judíos procedentes de una amplia área, fundamentalmente de cultura o influencia islámica - en que quedarían comprendidas regiones tan distintas como el Norte de Marruecos o Turquía - y que se caracterizan por utilizar en su ritual religioso la liturgia sefardí, habiendo conservado lengua y tradiciones hispánicas". $(1999,133)$ 


\section{La endecha y el acto de endechar}

De acuerdo con algunas fuentes (Molho 1950; Alvar 1969; Díaz-Mas 1982; Muñoz Fernández 2009), la endecha es una expresión lírico-poética que se desarrolló en la época medieval, a través de la cual una persona o un grupo de personas dolientes expresaban su sufrimiento por la muerte de un ser querido o de alguna persona notable de la comunidad. En ellas se elogiaba al fallecido y se hacía una reflexión sobre la vida y la muerte. Estas composiciones líricas iban usualmente acompañadas de llantos, gritos, ululaciones y desfiguros corporales que contribuían a manifestar con mayor intensidad el duelo por el finado. Con el tiempo, el acto de endechar vino a formar parte del corpus de la poesía medieval hispánica bajo el nombre de planto popular, no sólo como representación de un sentimiento o un acontecimiento doloroso, sino también como género poético, particularmente entre las comunidades judías de España en las que el endechar a un difunto ya era una tradición desde los tiempos bíblicos; sirvan como botón de muestra los siguientes pasajes extraídos de la Tanaj (Biblia judía).

Por tanto, así dijo el Señor, el D-os de los ejércitos: En todas las plazas habrá llanto, y en todas las calles dirán: ¡Ay! ¡Ay! Y al labrador llamarán a lloro, y a endecha a los que endechar supieren. (Amós 5:16)

Esta es la endecha, y la cantarán; las hijas de los gentiles la cantarán; endecharán sobre Egipto, y sobre toda su multitud, dijo el Señor D-os. (Ezequiel 32:16)

¡Atención! Manden llamar a las mujeres que tienen por oficio hacer lamentación. ¡Sí, que vengan pronto y que hagan lamentación por nosotros, que se nos llenen de lágrimas los ojos y nuestros párpados se inunden de llanto! (Jeremías 9:17-18)

Las endechas, cantadas en un lenguaje popular, se adaptaban a cualquier tipo de difunto (un hijo, un marido, una hija, una persona notable de la comunidad, etcétera). A propósito, Alvar señala:

El planto popular tiene carácter más espontáneo; está motivado por cada uno de los hechos luctuosos (la muerte, salida del cadáver, entierro, soledad tras la inhumación) y en cada momento la misma endecha repetida ha de tener acomodación distinta e, incluso, el mismo motivo se varía para hacerlo valer a personas diferentes. $(1969,33)$

Ahora bien, en la Edad Media, el acto de endechar o hacer planto era realizado cardinalmente por las endecheras (plañideras), mujeres asalariadas que eran contratadas para los velorios y cortejos fúnebres. Estas mujeres, que en su mayoría eran judías, 
no sólo lloraban con efusivas lágrimas la muerte del difunto, sino que también, como ya se mencionó, gritaban, vociferaban, se rasgaban la ropa, se desgreñaban, se arañaban la cara, se abofeteaban a sí mismas, se tiznaban con cenizas el cuerpo, al tiempo que interpretaban las endechas. De ahí el conocido proverbio que refiere a "la judía de Zaragoza, que cegó llorando duelos ajenos", el cual, sin duda, alude a este viejo oficio mujeril de emplearse para endechar a los muertos. ${ }^{3}$ Con respecto a los desfiguros corpóreos que acompañaban el acto de endechar, Filgueira Valverde comenta:

... fazían grandes duelos e desaguisados por los muertos. Así que algunos había que non querían comer nin beber fasta que morían, e otros que se mataban con sus manos, e otros que tanto ponían el duelo en el corazón que perdían el seso, e los que menos desto fazían mesaban los cabellos, e tajabanlos e desfazían sus caras, cortándolas e rascándolas. $(1945,516)$

En la España medieval, la ausencia de una exhibición pública de duelo habría indicado una falta de amor y respeto por el difunto. En las manifestaciones mortuorias, el llanto es una expresión de pena y dolor universal que se asocia con el luto y el duelo; el primero de carácter social (externo) y el segundo, más personal (interno). Muñoz Fernández señala:

El luto se define como el conjunto de prácticas sociales y procesos psíquicos suscitados por la muerte de una persona durante cierto lapso de tiempo, mientras que la fase de duelo está hecha de los elementos internos y angustiosos que acompañan al luto; por ello correspondería fundamentalmente al ámbito psíquico y emocional. $(2009,107)$

Aunado a las expresiones de dolor, ya sean vocales, corporales o emocionales, el acompañamiento de un instrumento musical durante el acto de endechar era algo muy común, sobre todo entre las comunidades judías donde se acostumbró tocar

3 La alusión a este refrán fue extraída del Florilegio, en el cual se explica que: "Esta judía de Zaragoza sería probablemente una de aquellas mujeres que, con los nombres de endechaderas o plañideras, se asalariaban en lo antiguo para acompañar al entierro de los difuntos, llorando estrepitosamente, haciendo mil gestos de dolor, llevando la cabellera suelta y rasgándose los vestidos." (Sbarbi y Osuna 1873) 
el adufe - un tipo de pandero con doble membrana- y la flauta, ${ }^{4}$ durante la procesión al cementerio.

En términos generales, el acto de endechar tenía una doble finalidad: por un lado, la de intensificar el dolor por el difunto y, por el otro, la de mitigar el dolor de los deudos. No obstante, debido al daño corporal que éste ocasionaba en las personas que lo realizaban, fue prohibido en varias ocasiones tanto por las autoridades internas de la judería (rabinos) así como por las externas (las alcaldías), al grado de multar a aquéllos que lo llevaran a cabo, por lo que poco a poco fue cayendo en desuso en toda la península ibérica. ${ }^{5}$ Pero fue en el exilio donde el acto de endechar y las endechas se lograron conservar gracias a la mujer judía sefardita, quien se convirtió en la guardiana y transmisora intergeneracional de esta tradición mortuoria. En el norte de Marruecos, la interpretación de las endechas entre las mujeres de la comunidad judía sefardí continuó con fuerza hasta entrado el siglo xx (Alvar 1969; Díaz-Mas 2008; Muñoz Fernández 2009), posteriormente, comenzó a declinar. Manuel Alvar (1969) sólo logró rescatar trece endechas durante el estudio de campo que realizó entre las comunidades sefarditas de esta región, justo cuando estos cantos lúgubres ya casi estaban extintos. De ahí la importancia de realizar un análisis de ellos desde una perspectiva de la semiosfera del texto (Lotman 1998) porque, como veremos en este estudio, las endechas arrojan luz sobre las costumbres y creencias luctuosas judeoespañolas medievales.

\section{La semiosfera del texto}

Antes de analizar la estructura y el contenido semiótico de las endechas judeoespañolas, conviene precisar qué se entiende por semiosfera del texto. De acuerdo

4 En la Tanaj (Biblia judía), cuando se hace referencia a las endechas, se dice que en ellas al menos toquen dos flautas para acompañarlas. La flauta era un instrumento musical muy apreciado entre las antiguas comunidades hebreas, aparece tanto en cantos de boda (flauta de las bodas) como en las endechas (flauta de los muertos). Tanto la flauta como el adufe aparecen mencionados en varios pasajes de la Tanaj.

5 La periodista Analise Infante (2009) asegura que, en algunas zonas rurales de España, aún quedan remanentes del acto de endechar a través de las plañideras (o lloronas) del siglo XXI. Mujeres católicas y rezanderas quienes, a diferencia de sus predecesoras judías medievales, lloran y oran de manera discreta cuando alguien muere en algún pueblo. Por llorar y rezar en un velorio, estas plañideras del siglo xxi reciben una paga por sus servicios. Disponible en: https://www.bbc.com/mundo/cultura sociedad/2009/11/091103_espana_planideras_rg 
con Iuri Lotman ${ }^{6}$ (1998), la semiosfera del texto es un término que alude al espacio semiótico en el que los humanos se encuentran inmersos. Al interior de este espacio se hallan todos los fenómenos culturales y las lenguas naturales, los cuales forman sistemas semióticos (de signos) que se construyen a partir de sus interacciones entre sí. Además, dicho espacio semiótico es el único lugar en donde se puede dar una semiosis, es decir, cualquier forma de actividad, conducta o proceso que involucre signos y la creación de significado. El proceso de semiosis se desarrolla en la mente del intérprete como resultado de la operación de tres elementos: un signo, su objeto y el intérprete.

Figura 1. Proceso de semiosis

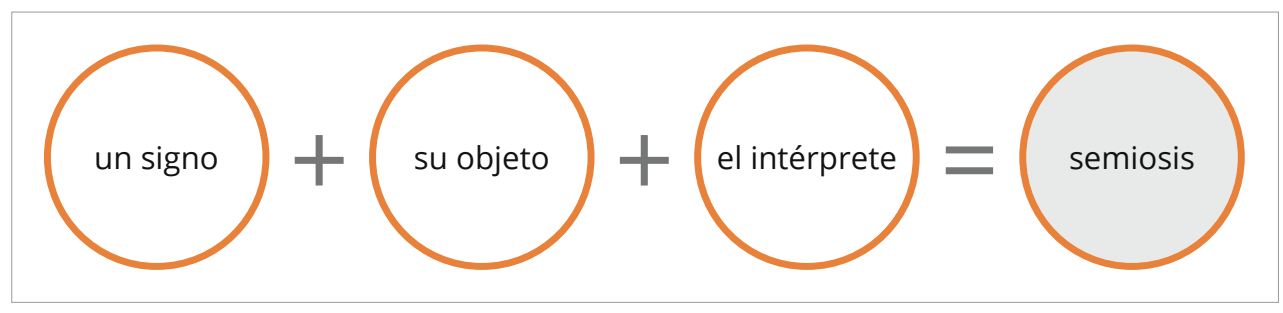

Elaboración: Norma Rosas Mayén

Con base en el diagrama anterior, podemos definir la semiosis como el proceso de la asociación de signos en la producción de significación interpretativa.

Si consideramos lo ya mencionado, analizar la semiosfera de un texto equivaldría a considerar la totalidad de los símbolos de una cultura y las interacciones que los individuos forjan con ellos, lo cual se refleja en sus actos comunicativos. Ese "espacio semiótico", en un sentido abstracto-metafórico, está ocupado por formaciones semióticas de diversos tipos (culturales y lingüísticas) que se hallan en diversos niveles de organización (Lotman 1998). De ahí que la semiosfera del texto carezca de uniformidad interna.

Así, al analizar las endechas judeoespañolas desde una perspectiva semiosférica, vamos a observar que, aunque estos textos no posean aparentemente una uniformidad interna, contienen formaciones semióticas de diversos tipos que no están

6 Iuri Mijáilovich Lotman (1922-1993) fue un investigador de la Universidad de Tartu (Estonia) de reconocida trayectoria internacional, cuyos aportes en el ámbito de la Semiótica de la Cultura trascendieron las fronteras de la entonces Unión Soviética, a pesar de las dificultades y censuras impuestas por el gobierno comunista a la difusión de su obra. Su labor de investigación abarcó toda una diversidad de problemas más allá de la teoría semiótica, para adentrarse en la mitología, el cine, la historia de la cultura, la estética, el teatro, la literatura, entre otros. 
aisladas ni son unívocas, sino que están relacionadas entre sí dentro de un espacio semiótico (semiosfera), el cual está esperando ser interpretado. Estos cantos fúnebres, como veremos más adelante, están dotados de una amalgama de signos de índole diversa que nos comunican todo un corpus de costumbres, tradiciones, expresiones lingüísticas, escenarios, en fin, toda una semiosfera de la cultura mortuoria judeoespañola que ha sido transmitida de manera oral $y$, por ende, adaptada y re-adaptada tanto diacrónica como sincrónicamente. La carencia de uniformidad interna de estos textos luctuosos quizá se deba a que la endecha, como acto catártico, no necesita comunicar ningún argumento lineal, sino que expresa breves e intensos destellos de sentimientos y emociones por la muerte de una persona, al tiempo que intensifica el sentimiento trágico que produce la muerte.

Al interior de cada endecha encontramos lo que Lotman (1998) llama "tendencias en tensión", tanto de integración como de desintegración. La integración es la conversión del contexto en texto y la desintegración es la transformación del texto en contexto. La siguiente figura ilustra de manera esquemática esta idea.

Figura 2. Tendencias de tensión (Lotman 1998)

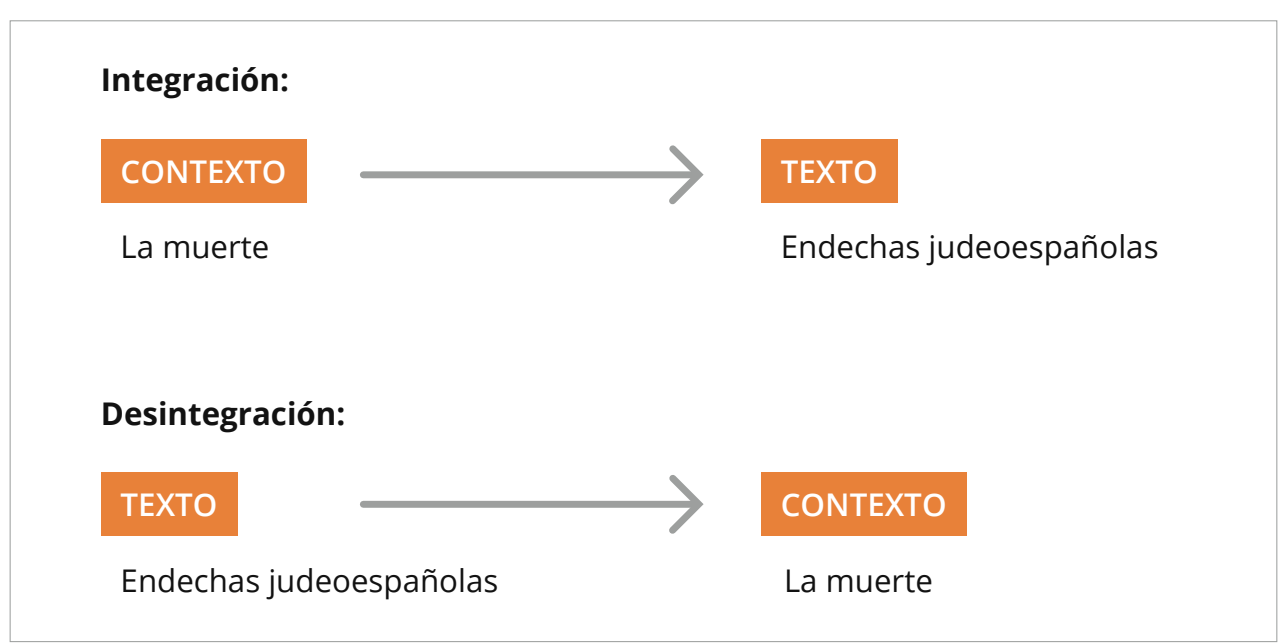

Elaboración: Norma Rosas Mayén

Según las funciones socio-comunicativas del texto establecidas por Lotman (1998), el texto no sólo transmite la información depositada en él desde fuera -en el caso de las endechas, a través de la tradición oral de una generación a otra y de un individuo a otro-, sino que también transforma el mensaje. En este sentido, las endechas judeoespañolas cumplen no sólo la función de una memoria cultural colectiva (un aspecto que es externo al texto), sino que también se convierten en una fuente de información (un aspecto interno del texto), pues al ser trasladadas a otro contexto geográfico-cultural (de la península ibérica al norte de Marruecos), funcionaron como receptoras de información para los miembros de la comunidad sefardita de 
esta región y, por extensión, para aquellos que nos interesamos en el análisis semiótico de estos textos.

\section{Estructura de la endecha judeoespañola marroquí}

El formato de las endechas, en general, es breve, se reduce con frecuencia a un lamento que se repite a lo largo de la misma y cuya finalidad es la de intensificar el dolor entre los deudos, o como lo dijera Bénichou (1968), su "fuerza fúnebre". En cuanto a su métrica, las endechas judeoespañolas usualmente constan de estrofas de cuatro versos de arte menor (de seis o siete sílabas) y de rima asonante en los versos pares, aunque existen algunas variantes -como, por ejemplo, la endecha mixta y la endecha real. ${ }^{7}$ Como se mencionó en el apartado anterior, algunas de ellas carecen de secuencia y uniformidad debido a su naturaleza semiosférica; entre los factores que inciden en ello se pueden mencionar: la inestabilidad de arbitrariedad de un sujeto a otro que afecta la transmisión oral, el entorno geográfico, el momento histórico y político, entre otros. Díaz-Mas al tratar de definir la naturaleza interna de las endechas, comenta:

[...] lo que define un romance de endechar no son precisamente sus características formales [...] ni tampoco su contenido [...] y mucho menos su origen y difusión geográfica. Lo que hace [...] un romance de endechar es algo sumamente inaprensible, escurridizo y difícil de delimitar para nuestra sensibilidad de lejanos observadores: ese algo es que en un momento determinado el romance se sienta como apto para aumentar la tensión afectiva del momento, para acrecentar el dolor y facilitar la catarsis del cantor y de los oyentes. $(1980,105)$

Asimismo, por su carácter semiosférico, la temática de las endechas puede variar desde reflexiones de tipo moral sobre la vida, la muerte como algo inevitable, la frustración por la partida de una persona, la soledad en la que se quedan los vivos, entre otros temas. ${ }^{8}$ Manuel Alvar (1969) clasifica el inventario de las endechas que recogió en su estudio etnográfico en seis temas: 1) de malogrado, [Textos I y II]; 2) descriptivas, [Textos III y IV]; 3) aquéllas en las que incurren palabras del moribundo o del muerto, [Textos V, VI y VII]; 4) las que describen la procesión al sacar el cadáver de casa [Textos XVIII, IX y X]; 5) las endechas tradicionales hispánicas

7 La endecha mixta alterna versos de seis o siete sílabas con otros de cinco (6/7-, 5a, 6/7-, 5a) y la endecha real alterna versos de seis sílabas con otros de once (6-, 6a, 6-, 11A).

8 No todas las endechas estaban dominadas por el tono fúnebre y luctuoso; algunas, por su carácter popular, acogieron temas nostálgicos e incluso amorosos. 
[Textos XI, XII y XIII]; y 6) las de la literatura moderna [Texto XIII]. En el próximo apartado se analizan las endechas más representativas de ese corpus (Textos I, II, IV, V, y VI), ya que su semiosfera ofrece interesantes datos de los rituales y creencias fúnebres de las comunidades sefarditas del litoral norte de Marruecos.

\section{Un análisis semiótico de las endechas}

\section{Texto I}

En la tradición judía, el morir a una edad muy avanzada es considerado una bendición, porque se deja tras de sí todo un legado de experiencias y valores tanto en el seno familiar como en la comunidad. ${ }^{9}$ Por el contrario, el morir joven es visto como una desgracia. La endecha I es precisamente un canto luctuoso dedicado a aquellos que mueren en plena juventud, es decir, malogrados. Así lo pone de manifiesto el estribillo intercalado que se repite en las primeras cuatro estrofas.

\author{
Malogrado muere, \\ malogrado ya se moría, \\ maique a todos duele \\ cuando se guardan de la luz del día. \\ ${ }^{5}$ Malogrado muere \\ de hermosa frente, \\ maique a todos duele \\ cuando no aljadra nadie de su gente. \\ Malogrado muere \\ 10 de ojos pintados, \\ maique a todos duele \\ cuando no se casa y deja un deseado. \\ Malogrado muere \\ de cara pintada, \\ 15 maique a todos duele \\ cuando no trae la novia a su casa.
}

9 Entre los judíos de la diáspora es muy frecuente escuchar la expresión ¡Que vivas 120 años! como una de las bendiciones más grandes y afectuosas entre las personas que se quieren. Esto es porque en el judaísmo cabalístico los números tienen siempre algún significado y el 120 es uno de ellos. En lengua hebrea hay una variante de esta expresión: ¡Hasta los 120 como a los 20 !; es decir, que la persona viva con el mismo aspecto, la misma capacidad y salud que tenía a los 20. malogrado

Una persona joven, un adolescente.

\section{aljadrar}

Reunirse, estar presente.

pintado

Hermoso, bonito, bello, lozano. 
La finalidad de la repetición de este estribillo, como ya se dijo, es intensificar el dolor entre los deudos y ensalzar el cortejo fúnebre que se hacía de la judería al cementerio. En el imaginario judeoespañol, la muerte de los que morían en la flor de la vida era un infortunio, un signo de mal agüero. Esto de algún modo puede explicar el por qué entre las comunidades sefarditas, todavía hoy, el cantar endechas fuera del mes de Tiš ‘́ beab (la festividad luctuosa del pueblo judío) puede traer mala suerte. Al respecto Ortega comenta: "Jamás hablan los hebreos de la muerte, ni se comunican noticias de un fallecimiento. Para este caso se valen de un signo hecho con la mano, que equivale a decir: ¡Fulano... se marchó!" $(1919,167)$. Con el fin de complementar el comentario de Ortega, Manuel Alvar nos cuenta sobre las dificultades que enfrentó para recolectar las endechas durante su investigación de campo en el norte de Marruecos:

Sabido es que la muerte, el morir, el cementerio, etc., son palabras que deben evitarse; del mismo modo trae mala suerte entonar endechas con las que se evoca el recuerdo de los familiares muertos. Largas horas y pacientes consuelos me costó en Tetuán recoger los textos que publico y, al final, la negativa más absoluta de proseguir. En Larache fui más afortunado: encontré una vieja plañidera que, salvados los primeros escrúpulos, no tuvo inconveniente en recitarme los cantos que hoy transcribo. (Alvar 1969, 7-8)

En el entrevero del estribillo citado, se resaltan las características físicas de una persona que muere en la flor de la vida: joven, de hermosa frente (sin arrugas), de ojos pintados (bellos y claros), de cara pintada (bonita y lozana). Asimismo, cada estrofa termina por aludir a alguna acción que el difunto no logró en vida por haber muerto joven e inesperadamente: sin ver el amanecer [cuando se guardan de la luz del día], sin reunirse con sus familiares [cuando no se aljadra nadie de su gente], sin casarse y tener hijos [cuando no se casa y deja un deseado], sin llevar a la novia a su casa [cuando no trae la novia a su casa]. Todas retratan las costumbres de la sociedad sefardita del exilio (Gutkowski 1999).

A las cuatro primeras estrofas les sigue una glosa [versos 17-20] que complementa el mensaje central del estribillo que es el llanto luctuoso, signo de un código antropológico que expresa la pena y el dolor de manera universal y que forma parte del acto de endechar.

\section{Ya limpié mis ojos}

con su ajuar y su alaría;

corren desmandadas,

20 cuando se guardan de las alegrías.

\section{alaría}

De acuerdo con Alvar (1969), alaría deriva del vocablo árabe al-hadiyya > arjadía que significa: presente, don, regalo. Considerando el contexto en que aparece este término, refiere a un regalo de bodas.

\section{desmandada} Abundante. 
En la glosa anterior observamos la coexistencia de dos signos en códigos esencialmente diferentes, la palabra y el gesto. En el primero, las palabras se sirven de una figura retórica, la elipsis, para describir el llanto. En el segundo, el gesto nos lleva al mundo lacrimal, estrechamente unido a la acción de llorar, en la que las lágrimas - elididas en la elipsis (corren desmandadas, cuando se guardan de las alegrías) - son las protagonistas que expresan el llanto por los difuntos. En este contexto, las lágrimas, como signo visual, interactúan con la acción de plañir el dolor, que es una manifestación del duelo.

Los versos que siguen [21-25] se valen, nuevamente, de una elipsis para referir al momento de la muerte del difunto, la cual ocurre poco antes del amanecer ( $y$ ande el sol no salía), y es anunciada a través de ululatos ( $y$ ayujo y ayujo) y los graznidos de un águila negra que se personifican en voces, y que propician los gritos [las voces] de los muchachos y las muchachas (las voces de mancebos y argasbas).

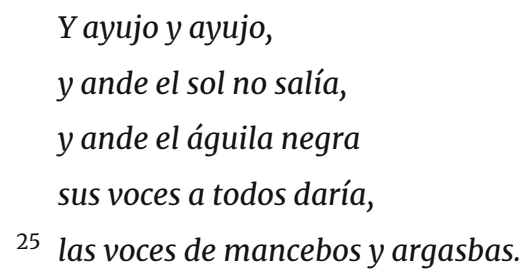

Conviene hacer notar que, simbólicamente, el águila es considerada un ave que no se deja intimidar por los espíritus de los muertos y que actúa como mediador entre el cielo y la tierra o, dicho de otro modo, entre el mundo espiritual y el mundo terrenal (Blaschke 2001). Esto explica por qué se hace referencia en estos versos al águila y no a otro animal.

La endecha I termina con la voz de la madre del difunto exclamando:

¡Quién me diera las uñas

de un gavilane!,

desde que se ha muerto mi hijo, yo viviendo en pesare.

30 ¡Y ay los nidarales!, yo me era de las bien casadas, no era de envidiarme.

En la estrofa anterior resulta interesante la alusión al gesto de carpido [versos 26 y 27], que forma parte, al igual que el llanto, del repertorio de expresiones que acompañan el acto de endechar, valiéndose de un símil que compara las uñas de la madre con las de un gavilán para arañarse y desgreñarse. Sabido es que las uñas del gavilán

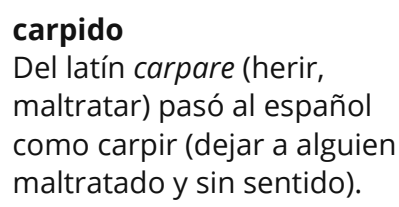
maltratar) pasó al español como carpir (dejar a alguien maltratado y sin sentido).

nidaral Nido. 
son sumamente incisivas - finas y afiladas para prender y desgarrar a sus presas con más facilidad-, por lo que dicha comparación transmite al lector el dolor tan intenso y desgarrador que se siente a causa de la muerte de un ser querido, en este caso, un hijo. Un dolor que destroza el corazón de una madre desangrándolo.

Los tres últimos versos [30-31] se valen otra vez de una metonimia que reemplaza nido por casa y, por consecuencia, las cualidades de una buena esposa judía con las cualidades de un gavilán hembra, siendo esta última muy buena para construir su nido y criar a sus polluelos. Esto se infiere del significante nidarales (nidos), que en la endecha refiere al hogar en un contexto exclamativo y a la condición de una buena esposa [yo me era de las bien casadas, no era de envidiarme]. Tradicionalmente, la mujer judía era educada para el matrimonio y la maternidad; su papel quedaba limitado al cumplimiento de sus obligaciones derivadas de su condición de esposa y madre, así como a la realización de los trabajos domésticos (Cantera Montenegro 1989).

\section{Texto II}

Para entender el contenido semiótico del Texto II, conviene recordar el tipo de actividades que realizaban usualmente los judíos durante la Edad Media. A lo largo de la historia se ha creado un estereotipo del judío dedicado a la usura, a los arriendos y al comercio, así como también su participación en la medicina, las actividades fiscales y financieras, entre otras de menor raigambre como son las artesanales y las textiles. Sin embargo, en algunas fuentes históricas (Hinojosa Montalvo 2000; De Antonio Rubio 2009), los judíos no sólo aparecen en el contexto urbano sino también en el rural, en el que realizan trabajos relacionados con la agricultura que variaban según la región. Entre los principales cultivos estaban los cereales y los de huerta de regadío, especialmente los viñedos, debido al papel que el vino kasher ${ }^{10}$ jugaba en la dieta judía.

Si partimos de este supuesto, las primeras cuatro estrofas de la endecha del Texto II [versos 1-23] están contextualizadas en un ámbito rural; desde los primeros cuatro versos y a través de estribillos parciales intercalados que se repiten y refuerzan la contemplación de la tierra sembrada de trigo y cebada.

\section{A la tierra iría, con dolor l'arrobaría}

10 El vino que es hecho siguiendo los estatutos alimenticios y de limpieza que prescribe el judaísmo.

\section{arrobar}

Del verdo arrobar. Sinónimo de embelesar que significa cautivar los sentidos, contemplar. 


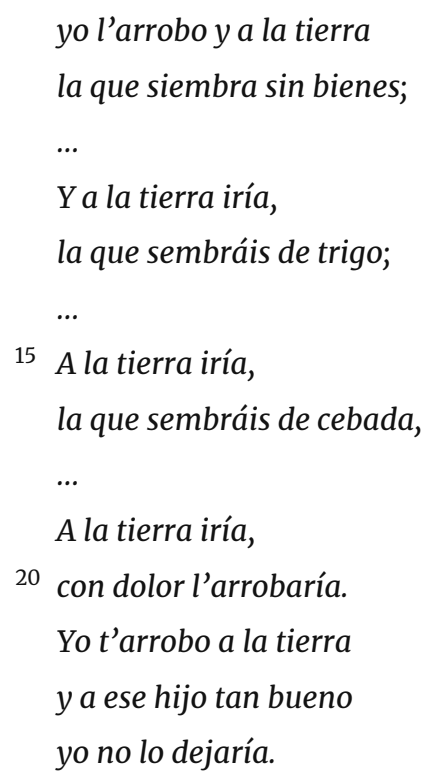

En el entramado de este estribillo parcial se da información acerca del uso del paño de tumba, con el que se cubría o envolvía el cadáver del difunto según la costumbre mosaica.

${ }^{5}$ que le pudra los sus paños

y no su hermosa frente;

$\cdots$

17 que le pudra los sus paños

y no su cara pintada.

$\ldots$

De acuerdo con algunas fuentes (Molho 1950; Alvar 1969; Rouach 1990; Zafrani 2001), el paño de tumba podía ser de color negro para un adulto, o bien blanco para un niño o un adolescente. La endecha del Texto II hace referencia a un muerto joven, esto se deduce de los versos [31 y 35] a través de las palabras que entabla el moribundo con su madre antes de morir (si mal durmiera) en la última estrofa [versos 28-37].

Si mal durmiera,

la mi madre, en vuestra halda

30 cobriésemes la mi cara

con el velo de los mancebos y arasbas.

Si mal durmiera,

la mi madre en vuestros brazos, cobijemes la cara

35 con el velo de los malogrados.

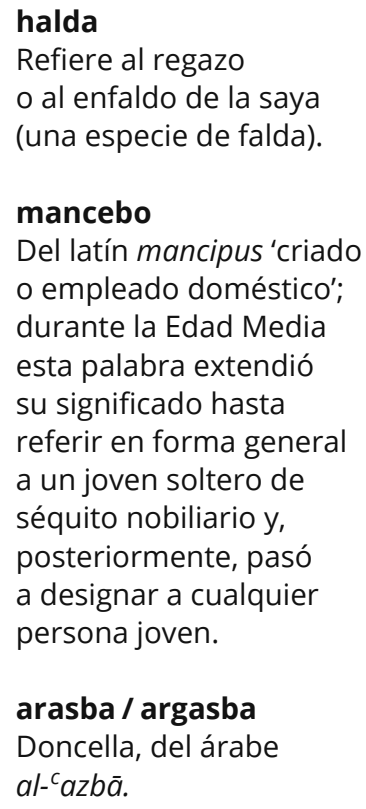


Indudablemente, el foco de esta endecha es la juventud del difunto que muere joven (malogrado) y sin dejar descendencia, como se aprecia en los siguientes versos.

$\cdots$

Se van los novios chiquitos

y no crían sus hijos.

...

Y si este dolor fue tan grande,

doblarlo ha el pesare,

se van mancebos $y$ arasbas

y vacían su lugare.

Los versos anteriores que se resaltan nos proporcionan información sobre una de las máximas talmúdicas que es la de contraer matrimonio en una edad joven ${ }^{11} \mathrm{y}$ procrear familia, pero que, en esta endecha, debido a una muerte prematura, no se cumple. Al respecto, Cantera Montenegro señala: "Para el judaísmo la vocación del hombre y de la mujer debe ser la unión fecunda, lo que tiene su justificación en el precepto divino de «creced y multiplicaos» (Génesis, 1, 28)" (1989, 41). En la misma veta, Molho comenta:

Para un hombre casado, el más vivo deseo era tener una numerosa progenitura en la que dominase el sexo fuerte, porque los varones, que estaban llamados a perpetuar el nombre familiar, eran los destinados a dar al padre, cuando fuese viejo, confortación y alivio y, después de su muerte, rezar el Qaddiš para el reposo del alma del difunto. $(1950,50)$

La endecha concluye con un par de versos exclamativos en la boca del moribundo, que aluden al gavilán.

$\cdots$

iQue madre me llamaba

de ese gavilán pintado!

La mención del gavilán tanto en el Texto II como en el Texto I, anteriormente analizado, puede obedecer quizá a que esta ave posee un enérgico vuelo cuando es joven.
Qaddiš (o Kaddisch) Oraciones y costumbres para la celebración del recuerdo del alma y por el tiempo de duelo.

11 En la época post-bíblica la legislación rabínica favoreció los matrimonios de edad temprana, de tal modo que la edad mínima para contraer matrimonio se fijaba a los trece años para los varones y a los doce para las mujeres. En España la edad para casarse en las comunidades judías era alrededor de los quince años para los hombres y dieciséis para las chicas. 
Asimismo, el adjetivo pintado (lozano) refuerza la imagen de una persona que muere en la flor de la vida, que es el tema focal de los Textos I y II. De ahí que Alvar (1969) los haya puesto en la categoría temática de "malogrado".

\section{Texto IV}

Como se puede observar, el texto IV está compuesto de cinco cuartetas que inician con un estribillo parcial de dos versos que se intercalan al inicio de cada estrofa.

\author{
Háganle, le hagan \\ vestidos con mucho pesare, \\ que hoy se departe \\ de su casa y su lugare. \\ ${ }^{5}$ Háganle, le hagan \\ vestidos con muchas oínas, \\ para el golpe rabioso \\ no halló cura ni melecina. \\ Háganle, le hagan \\ 10 vestidos con mucha mancilla: \\ se van mocitos y arasbas, \\ no hacen alegría. \\ Háganle, le hagan \\ vestidos con mucho sospiro, \\ 15 se van los novios chiquitos \\ y no crían a sus hijos. \\ Háganle, le hagan \\ vestidos con mucha alcarja, \\ se van los novios chiquitos \\ 20 y vacían su casa.
}

El estribillo de este canto luctuoso describe cómo los sudarios de los difuntos eran confeccionados en una atmósfera de pesar, dolor, llanto y lamento colectivos. Esto lo sabemos por las palabras resaltadas en cada cuarteta: pesare (pesar), oínas (endechas), mancilla (dolor), sospiro (suspiros), alcarja (pena). Observamos entonces que el duelo no sólo se puede llorar a través de los ojos, sino también a través de la boca (cantos, llantos, gritos, suspiros) y de las manos (la hechura de la mortaja del difunto). Esto es lo que Lotman (1998) en su descripción de semiosfera llamaría fronteras semióticas (en esta endecha expresadas a través de los ojos, la boca y las manos) dentro de una unidad sémica (la endecha per se del Texto IV). Dichas

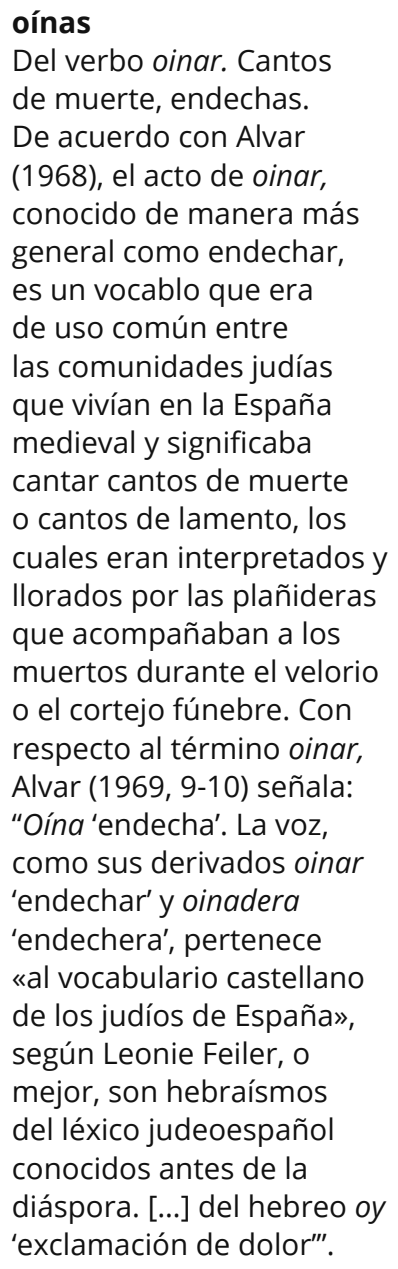
de muerte, endechas. De acuerdo con Alvar (1968), el acto de oinar, conocido de manera más general como endechar, es un vocablo que era de uso común entre las comunidades judías que vivían en la España medieval y significaba cantar cantos de muerte o cantos de lamento, los cuales eran interpretados y llorados por las plañideras que acompañaban a los muertos durante el velorio o el cortejo fúnebre. Con respecto al término oinar, Alvar (1969, 9-10) señala: “Oína 'endecha'. La voz, como sus derivados oinar 'endechar' y oinadera 'endechera', pertenece «al vocabulario castellano de los judíos de España», según Leonie Feiler, o mejor, son hebraísmos del léxico judeoespañol conocidos antes de la diáspora. [...] del hebreo oy 'exclamación de dolor'".

\section{mancilla}

Del latín macellare 'matar, abatir'. En este contexto, mancilla se refiere a realizar algo con abatimiento, es decir, sin ánimo, sin fuerza, con tristeza, con aflicción, con dolor.

alcarja Pena. 
fronteras semióticas cohabitan en el texto y sirven como intensificadores, en este caso, la transmisión de dolor por la muerte.

Asimismo, el estribillo de la endecha IV hace alusión a una de las actividades de la mujer judía medieval, que era la ocupación en el hilado de la lana, del lino o del cáñamo, labor que devenía en una actividad artesanal - la costura, el bordado y el trabajo textil-y que complementaba la prioritaria dedicación a su hogar. En el ámbito textil, algunas judías se dedicaban exclusivamente a la hechura de paños; se les conocía bajo el nombre de pañeras, la cuales elaboraban paños para toda ocasión, incluyendo mortajas. Al respecto Cantera Montenegro comenta:

De este modo, figuran en la documentación tintoreras, colchoneras, colcheras, chapineras, tejedoras, «labranderas» o costureras, pañeras, así como también alguna propietaria de tenerías. Asimismo hay alguna referencia documental a lavanderas, que creo que pueden tratarse de las encargadas de lavar la lana, tarea que constituía el primer paso en la producción textil. [El énfasis es mío] $(1989,57)$

Si regresamos a las mortajas, pareciera como si metafóricamente el acto de endechar entretejiera con dolor el sudario de los muertos, en especial el de los malogrados. Así lo reiteran los versos [11, 12, 15, 16, 19 y 20] de las tres últimas cuartetas, los cuales aluden a aquellos que se mueren jóvenes (se van mocitos y arasbas) / (se van los novios chiquitos), sin dejar descendencia (sin dejar alegría), sin criar a sus hijos (y no crían a sus hijos), dejando su hogar vacío (y vacían su casa).

En cuanto a la preparación del cadáver, los relatos bíblicos y algunas fuentes (Molho 1950; Rouach 1990; Ehrlich 2006) revelan lo meticulosos que eran (y son los judíos todavía) al preparar los cadáveres para su entierro. Primero se acostumbraba lavar el cuerpo del difunto (rehisá), acto seguido se impregnaba con especies aromáticas y después se ungía con buenos aceites ${ }^{12}$ para, finalmente, envolverlo en un simple sudario $^{13}$. En el judaísmo es importante respetar los preceptos de este ritual, se trate de alguien con o sin recursos, ya que, en la cosmogonía judía, la muerte iguala a todos los seres humanos.

\author{
mortaja \\ Proviene del latín \\ mortualia, que significa \\ relativo a un muerto. \\ Es una pieza de lino \\ parecida a una sábana, \\ que sirve para envolver \\ el cuerpo del difunto \\ antes de colocarlo \\ en el sepulcro.
}

12 Entre las comunidades judías tradicionales, la unción y la preparación del cuerpo requiere una mezcla especial de especias, esencias y aceites (sándalo, mirra, nardo, mirto, pino, abeto, aceite de oliva extra virgen, entre otros). Estos bálsamos se han utilizado durante cientos de años para la preparación y purificación de los muertos. Es casi posible que esta práctica haya sido adoptada de otras culturas anteriores a la hebraica, como la egipcia.

13 Consúltese la Biblia, Juan 19:39-40; Hechos 9:36-41. 


\section{Texto V}

Antes de abordar la endecha $\mathrm{V}$, conviene subrayar que en el judaísmo la muerte es una extensión o continuidad del ciclo vital. De ahí que el ser humano esté dotado de dos componentes: un cuerpo y un alma. El primero es una especie de vehículo terrenal dotado de límites, es decir, mortal. El alma, por otro lado, es una entidad espiritual e inmortal, la cual continúa activa dentro de la comunidad y sigue en contacto con sus familiares, procurando el bienestar de los mismos. En otras palabras, el alma pasa a ejercer la función de un intercesor espiritual.

Si consideramos lo anterior, la primera estrofa de la endecha $\mathrm{v}$ alude al alma del difunto [versos 1-2], cuyo cuerpo ha dejado de existir en este mundo, pero su alma yace en la Casa de la Eternidad, es decir en el cementerio [versos 3-4].

\footnotetext{
"Ni anda ni parece

ni le veo como solía,

${ }^{3}$ que la tierra hizo morada

por siempre y toda la vía”.
}

En la fe mosaica, el entierro en el cementerio es considerado como la vuelta al hogar, a través del cual el difunto se reúne de nueva cuenta con sus antepasados. De ahí, la fórmula que se acostumbra a grabar en los epitafios lapidarios para recordar a un difunto fhî nismatô frûrcl bi-fror ha-hayyím, abreviada con cinco letras hebreas (הבץנת) que significan literalmente sea su alma atada al mundo de los vivientes, lo cual equivaldría a decir "que su alma esté unida a los lazos de la vida eterna de los suyos", expresión que alude a la eternidad del alma (en el verso 4: por siempre y toda la vía). Las siguientes fotografías muestran dicha expresión abreviada en algunas tumbas del cementerio judío de Tánger en Marruecos.

Figura 3. Tumbas del cementerio judío de Tánger (Marruecos, 2016) con la fórmula epitáfica judáica.
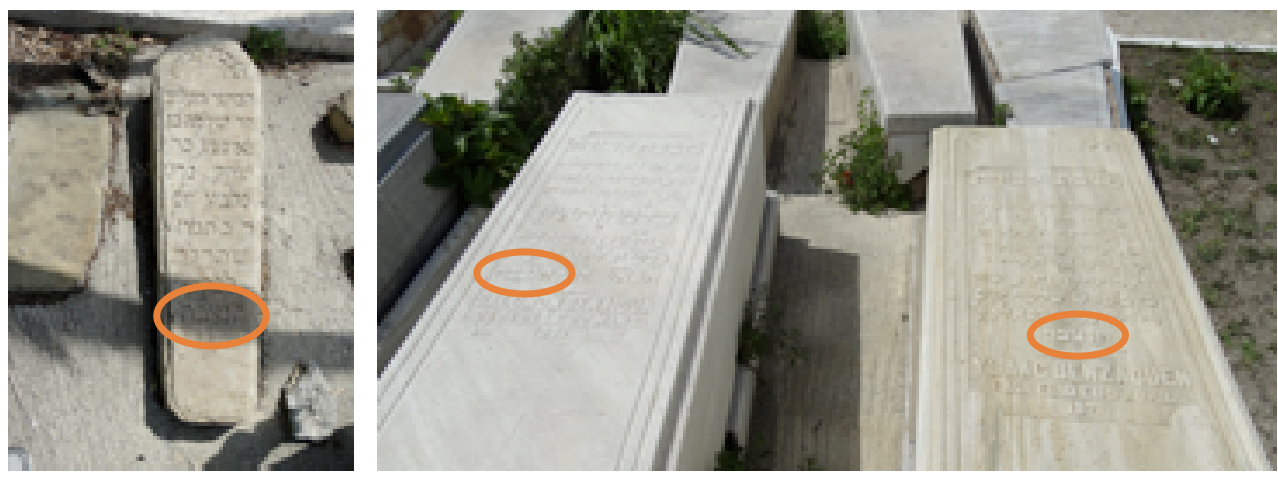

Fotografías y elaboracion de la composición de Norma Rosas Mayén 
En la siguiente estrofa [versos 5-9], la voz del alma del difunto se deja oír amargamente, establece un diálogo de dolor y añoranza con su madre por la vida que le fue arrebatada.

$$
\begin{aligned}
& 5 \text {-"Si subieras, mi madre, } \\
& \text { y al campo por la mañana, } \\
& \text { pregunta a los corantados } \\
& \text { cómo es el trago de la retama, } \\
& \text { amargo y preto". }
\end{aligned}
$$

En el plano tangible, el alma del difunto sufre la separación de su madre, persuadiéndola de que suba al cementerio [al campo] por la mañana y les pregunte a las almas de los muertos [los corantados] lo amargo que es despojarse de la vestimenta terrenal, el cuerpo. Ese tono de amargura se lo da el vocablo retama, una planta silvestre de la que brota una flor de color blanco-amarillento cuyo sabor es amargo al ser destilada.

En cuanto al vocablo preto [negro], en este contexto, alude al primer periodo luctuoso judío conocido como Shiv'ah (siete), el cual consta de siete días después del entierro y prescribe vestirse con ropa oscura. ${ }^{14}$ En el judaísmo, durante este primer periodo luctuoso, los pensamientos de los deudos se concentran en la memoria del ser querido que han perdido y no deben salir de sus casas, salvo por asuntos de fuerza mayor (De Lange 2011). Es interesante observar que, en esta estrofa, el dolor del alma del difunto es tan intenso que persuade a su madre para que salga de su hogar y vaya al cementerio en un periodo en el que la prescripción del luto judaico, como se acaba de mencionar, no lo permite.

La tercera cuarteta [versos 10-14] alude de nueva cuenta al cementerio, lugar donde moran las ánimas de los difuntos o, como dicen los rabinos: "donde flotan sobre las tumbas las almas de los muertos".

${ }^{14}$ Los antiguos hebreos se vestían con una túnica de cilicio como una expresión de duelo. El cilicio era una tela oscura y áspera tejida generalmente de pelo de cabra o de camello. Las personas se lo ponían encima de sí como señal de su duelo. Acostumbraban también arrojarse tierra o cenizas sobre sí mismos. El vestirse de cilicio y echarse ceniza indicaba un profundo arrepentimiento y una voluntad de cambio y transformación interior a una vida sencilla, humilde y lejos de las vanidades de este mundo, de lo cotidiano y rutinario. Era tiempo de reflexión sobre su propia vida y meditación profunda en Dios. Para ilustrar, sirvan como ejemplo los siguientes pasajes bíblicos extraídos del Antiguo Testamento. Génesis (37:34): "Entonces Jacob rasgó sus vestidos, y se puso cilicio sobre sus lomos, y guardó luto por su hijo muchos días." Lamentaciones (2:10): "Se sentaron en tierra, se callaron los ancianos de la hija de Sion; echaron polvo sobre sus cabezas, se ciñeron de cilicio; las vírgenes de Jerusalén bajaron sus cabezas a la tierra". 
10 "Ni anda ni parece,

ni le veo hoy como solía,

$y$ entre montes $y$ valles,

allí se escondía".

En la antigüedad, por lo general, los cementerios judíos se situaban bien al otro lado del río o bien en lugares elevados y apartados, como se puede deducir del verso 12 de esta endecha (yentre montes y valles). Con respecto al emplazamiento de cementerios judíos, Casanovas Miró señala:

Por razones de salubridad, los cementerios judíos se situaban extramuros y en ocasiones a considerable distancia, en lugares ligeramente elevados y orientados, siempre que esto fuera posible, hacia el sector donde se encontraba el barrio judío (Barcelona, Girona). En Barcelona, el recorrido desde la ciudad hasta el cementerio era largo y penoso, ya que además había que subir una empinada cuesta. No menos largo era el trayecto desde la ciudad de Zaragoza hasta la necrópolis situada en Miralbueno. En otros lugares ésta se levantaba en un lugar cercano a las murallas (Murcia, Valencia, Córdoba) y junto a una de las puertas de la ciudad o al otro lado del río cerca de un puente que servía de enlace entre la necrópolis y el barrio judío (Segovia, Plasencia, Besalú). (2003, 209)

En la cuarta estrofa [versos 14-17] se vuelve a escuchar la voz del difunto, la cual anda merodeando por la que fue su casa después de haber pasado el primer periodo de luto (Shiv'ah). Esto se deduce de los versos 14 y 15, los cuales describen la ausencia de cirios a los costados del que fuera el lecho del difunto (tálamo). Una costumbre que se realizaba durante los primeros siete días después de haber fallecido la persona. ${ }^{15}$

"Un tálamo vidi armado

15 sin cirios y candelares;

ansina hacen los maridos buenos, vácian su casa y su lugare.

Los versos 16 y 17 simplemente intensifican la nostalgia del difunto por el que fue su hogar. La endecha continúa describiendo, en voz del difunto, lo que éste ve sobre el que fuera su lecho, refiriéndose a la ropa que acostumbraba a ponerse en los días festivos (el sábado y la Pascua).

\section{tálamo}

Lecho conyugal, cama de los desposados.

candelares

Velas, candelas.

15 De acuerdo con algunos investigadores (Ortega 1919; Molho 1950: Alvar 1969), estas costumbres cumplen el periodo de margen que exigen todos los ritos de paso. 
Yel tálamo vidi mal armado

tapado con la ropa que pone

20 el sábbay y la Pascua.

Para los judíos, vestir ropa especial y limpia en los días festivos, especialmente los sábados (sábbay), es una costumbre muy arraigada. Con respecto a la costumbre de la celebración del sábado, Bel Bravo comenta:

El aire de fiesta se nota no sólo en el descanso, sino también en la comida que es especial, más cuidada. De la misma manera, todo el mundo se cambia de ropa, y a esto se alude en la causa contra Joana de Rojas: 'y vestirse los sabbados camisa limpia y rropa limpia". Por otra parte, es lógico que, si se aprovechaba este día para hacer visitas sociales y acogerlas, se usasen ropas limpias y mejores que las de a diario. $(2012,259)$

La endecha termina con la voz del finado narrando una de las costumbres que solía hacer la mujer judía al enviudar (se quema), que era el guardar la ropa festiva de su esposo en un baúl (el arca).

Y ansina hace la mujer cuando se quema, lo tiene guardado el arca".

Para concluir el análisis de los signos que se aprecian en esta endecha, es pertinente enfatizar que en el texto se alude de manera muy clara a dos mujeres: a la madre y a la esposa del difunto (la quemada); esto se debe a que, en el judaísmo, la mujer juega un papel esencial en la transmisión de los valores y la identidad religiosa en el plano familiar (Ortega 1919; Molho 1950; Alvar 1969; Díaz-Mas 2008). Como raíz espiritual de la educación, la mujer es responsable de que la religión, las costumbres y las tradiciones judías se transmitan de manera intergeneracional, de ahí que la mujer juegue un papel protagónico en las endechas como se ha venido observando.

\section{Texto VI}

El tono de la endecha vi es catártico, en ésta el moribundo sostiene un agitado diálogo con su madre al verse en el umbral de la muerte por una enfermedad intestinal que ningún remedio pudo aliviar.

El dolor tan intenso que siente el desahuciado y que finalmente lo lleva a la muerte está expresado a partir de la primera estrofa, la cual funciona como una sinopsis de la catarsis que describe esta endecha y en la que el moribundo, como última voluntad

\section{Sábbay}

Sábado, día festivo.

quemarse

Enviudar.

arca

Baúl. 
antes de que llegue su muerte (los viene el golpe rabioso), pide que se le intensifiquen los llantos (dobladas las oínas) de las plañideras.

Y este dolo fue grande,

dobladas las oínas,

los viene el golpe rabioso,

no llevan cura ni melecina;

condaba las manos al portillo:

"No me dejéis, mi madre,

irme he de ir contigo,

si ya me dejatis

jamás volveré".

${ }^{10}$ Condaba las manos a la puerta:

condaba

"No me dejéis mi madre, salir afuera".

A lo largo de la endecha, la voz del moribundo se deja oír una y otra vez, aferrándose a la vida y suplicándole a su madre que no lo deje solo (condaba las manos al portillo), porque de un momento a otro puede morir. Esto hace alusión a la costumbre judía de no dejar solos ni a los moribundos ni a los muertos.

Los versos 11 y 12 aluden de manera indirecta a la tradición judía de sacar y llevar a cuestas al difunto en procesión hasta el cementerio, acompañándole con endechas y otras manifestaciones de duelo. La figura 4, extraída de la Hagadá Dorada, ${ }^{16}$ ilustra este acontecimiento lúgubre.

Estos signos gestuales y emocionales, como se ha venido diciendo, eran realizados por las plañideras (en la imagen, las mujeres vestidas de negro que van al frente de la procesión) y por los familiares y amigos cercanos (en la imagen, los hombres que llevan a cuestas el cadáver) para avivar el dolor durante el cortejo fúnebre del difunto.

16 Hagadá, vocablo hebreo que significa literalmente "narración", es también el nombre del libro que se lee en los hogares judíos durante la cena y celebración que tienen lugar en la noche de Pésaj (la Pascua judía), momento en que se conmemora el Éxodo o salida del pueblo de Israel del antiguo Egipto. Este libro sirve de guía para organizar las plegarias y el desarrollo del Séder; la Hagadá de Pésaj es uno de los libros de oraciones judíos que con mayor frecuencia son iluminados e ilustrados. La Hagadá Dorada fue realizada probablemente en Barcelona hacia 1320 en lengua hebrea.
Poner, acercarse. 
Figura 4. Cortejo fúnebre (detalle de Hagadá Dorada)

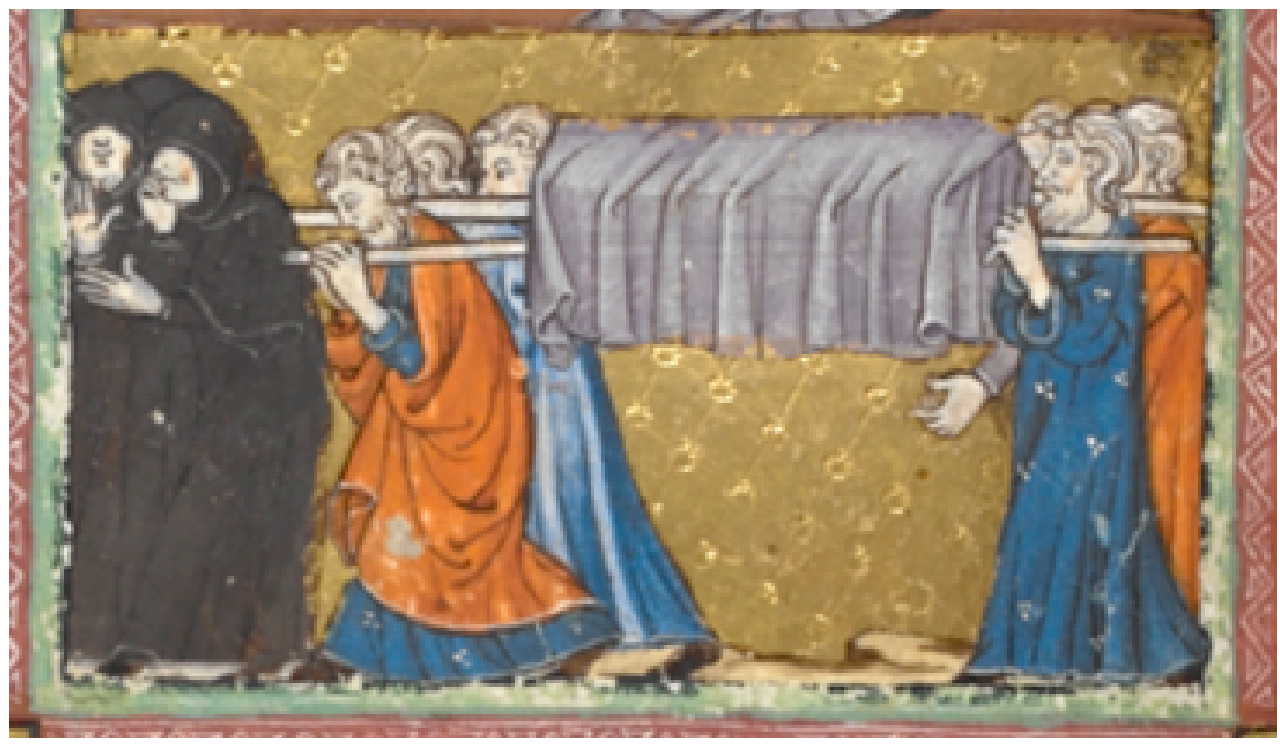

Fuente: "The Golden Haggadah now online", Medievalists.net https://www.medievalists. net/2017/01/golden-haggadah-now-online/\#jp-carousel-68046

Las últimas estrofas de la endecha VI hacen alusión a algunas partes del cuerpo que conllevan un significado muy especial en el judaísmo: la cara, las manos, los intestinos (estantinas).

Y alzara los sus ojos

y mirara de cara en cara:

15 "La mi madre, ya me muero, ya jamás me mirarás mi cara".

\section{Alzara las sus manos}

y apretóla de las estantinas:

\section{estantinas}

Intestinos, tripas.

A propósito de estos signos corporales (cara, manos e intestinos), el Zohar (El Libro del Esplendor), en la discusión dedicada al alma y al cuerpo, establece:

Los misterios relativos a los rasgos de la cara son solo conocidos por aquellos sabios que penetran en las profundidades de la sabiduría [...]. Las veintidós letras del alfabeto están impresas en cada alma y a su vez ésta las imprime en el cuerpo al cual anima; [...] si la conducta del hombre es buena, las letras están dispuestas en el rostro de una manera regular, si no, sufren una inversión que deja una marca en el rostro. [...] las líneas de las manos encierran grandes misterios, al igual que las de los dedos. [...] el estómago es imagen de la muerte, pues de allí suben los vapores que provocan el sueño. [El énfasis es mío] (Giol 2016,103-114) 
Como ya se ha mencionado, el alma está recubierta con una vestimenta terrenal que es el cuerpo humano. Al igual que éste, el alma cuenta con 248 órganos y 365 arterias espirituales. De ahí que el alma y el cuerpo están constituidos del mismo número de partes. Al tomar en consideración dicha paridad, los constituyentes espirituales del alma se entrelazan con los corporales para otorgarles vida y permitirles realizar sus funciones físicas. Por eso, cuando llega la muerte y el alma se separa del cuerpo, todas las partes físicas pierden su conexión espiritual que las mantenía con vida y dejan de subsistir en el plano terrenal (Giol 2016, 103-138). El momento en que el alma se despoja de su envoltura corporal está representado en los dos últimos versos [19 y 20] de esta endecha.

\footnotetext{
"La mi madre, ya me muero,

20 no me aprestaron las melecinas".
}

aprestar Servir, valer.

Estas palabras del moribundo (La mi madre, ya me muero) ponen fin a la escena catártica que se desarrolla a lo largo de la endecha vi, para finalmente aceptar la muerte, ya que ningún remedio sirvió para evitarla (no me aprestaron las melecinas).

\section{Conclusiones generales}

A lo largo de este artículo hemos presentado un análisis semiótico sobre el contenido de un género poético-lírico extinto, la poesía luctuosa del norte de Marruecos, conocida en su conjunto como endechas judeoespañolas. Vimos que estos cantos de muerte se conservaron entre las comunidades sefarditas del exilio, después de su expulsión de la península ibérica acaecida en 1492. La salida de su Sefarad, como los judíos llamaban a su España natal, supuso un continuo lamento, un rememorar la tierra perdida, una nostalgia que los motivó a mantener muchas de sus tradiciones, como la de endechar a sus muertos, por cerca de cinco siglos.

La importancia de las endechas radica en que encierran toda una semiosfera en su texto (Lotman 1998), es decir, una aglomeración de signos culturales y lingüísticos -en este caso relacionados con lo mortuorio y en lengua haketía - que formaban parte de la identidad de los judíos de la España medieval y que resulta difícil, a primera lectura, de apreciar. Nuestro análisis muestra que las endechas judeoespañolas carecen de una continuidad argumental entre sus estrofas debido a su carácter semiosférico, por lo que no siguen un orden fijo. Sin embargo, cada endecha encierra elementos relacionados con las costumbres y creencias luctuosas judeoespañolas medievales que se conectan al interior de un espacio semiótico (semiosfera), en donde la suma de sus elementos tanto culturales como lingüísticos es significativa. De ahí su valor no sólo literario sino también sociocultural. 
La endecha fue una poesía luctuosa expresada como un canto comunal que la costumbre y la tradición mantuvieron. El acto de cantar endechas fue, ante todo, una actividad cardinalmente femenina, siendo la mujer judía sefardita la depositaria, la guardiana y el agente de su transmisión. La repetición de estribillos que, como vimos, se entretejen en las endechas, facilitó la memorización y por ende la conservación y transmisión de estos cantos luctuosos a través de las generaciones. Estas mujeres llamadas endecheras (plañideras) jugaron un papel decisivo en la ejecución de estos cantos, los cuales acompañaban al son del adufe y la flauta con lamentos, llantos, entre otro tipo de gestos corporales impropios que agudizaban el dolor de los dolientes en los velorios y cortejos fúnebres, y convierten el acto de endechar en una verdadera catarsis. Después del siglo xV, todas estas expresiones de dolor y abatimiento en los funerales empezaron a entrar en decadencia en la península ibérica y fue la Inquisición la que las erradicó por completo. No obstante, la costumbre de endechar a los difuntos se conservó en el exilio marroquí, aunque con el paso del tiempo también se fue diezmando y, casi en su ocaso, un reducido corpus de endechas fue rescatado y transcrito por Manuel Alvar en la segunda mitad del siglo Xx.

Las endechas recogidas por Alvar son sólo el eco, a distancia, de lo que fue propiamente el acto de endechar en las comunidades judeoespañolas medievales y sefarditas del norte de Marruecos. No por ello esta poesía luctuosa pierde su fuerza y su invaluable carga semiótica - pues no hay que olvidar que el mundo de la cultura oral está lleno de signos ${ }^{17}$ utilizados en los rituales, los cuales poseen un amplio carácter polisémico derivado de esos rituales y textos orales de los que son signos mnemotécnicos. Por esta razón, las endechas judeoespañolas del norte de Marruecos apremiaban un análisis de su contenido semiótico que este estudio ha ofrecido. Quiero cerrar con las siguientes palabras de Lotman (1998, 82): "La escritura es una forma de memoria y si el texto (cultura oral) - a su vez- es memoria, entonces puede de-

cirse que todo texto es una escritura mediante un sistema de signos complejos que hablan de la cultura".-

\section{Referencias}

Alvar, Manuel. 1969. Endechas judeoespañolas. Publicaciones de Estudios Sefardíes, serie II, no. 2. Madrid: Consejo Superior de Investigaciones Científicas. Bel Bravo, María Antonia. 2012. Sefarad. Los judíos de España. Madrid: Silex. Bendayan de Bendelac, Alegría. 1990. Voces Jaquetiescas. Caracas: Centro de Estudios Sefardíes de Caracas, Asociación Israelita de Venezuela.

17 Aunque es verdad que, al transferirse la tradición oral a un formato escrito, en lugar de enriquecerse se empobrece la estructura semiótica de su cultura. 
Bénichou, Paul. 1945. "Observaciones sobre el judeoespañol de Marruecos." Revista de Filología Hispánica año VII, no. 3 (julio-septiembre): 209-258.

_. 1968. Romancero judeoespañol de Marruecos. Madrid: Castalia.

Blaschke, Jorge. 2001. Enciclopedia de los símbolos esotéricos. Barcelona: Ediciones Robinbook.

Cantera Montenegro, Enrique. 1989. "La mujer judía en la España medieval." Espacio, Tiempo y Forma, Serie III, Historia Medieval, tomo 2: 37-64.

Casanovas Miró, Jordi. 2003. "Las necrópolis judías hispanas. Nuevas aportaciones." En Memoria de Sefarad, 209-219. Toledo: Sociedad Estatal para la Acción Cultural Exterior.

De Antonio Rubio, María Gloria. 2009. Judíos e Inquisición en Ribadavia. Ribadavia: Concello de Ribadavia.

De Lange, Nicholas. 2011. El judaísmo. Madrid: Akal.

Delumeau, Jean. 2012. El miedo en Occidente. Madrid: Taurus.

Díaz-Mas, María Paloma. 1980. "Romances sefardíes de endechar." En Actas de las Jornadas de Estudios Sefardíes de Cáceres, 99-105. Cáceres: Universidad de Extremadura.

_..1982. Temas y tópicos en la poesía luctuosa sefardí. Colección Tesis Doctorales No. 191/82. Madrid: Universidad Complutense de Madrid.

_. 2002. "Quinot sefardíes y Complants catalanes: lamentaciones por las ciudades santas perdidas." En Judaísmo Hispano: estudios en memoria de José Luis Lacave Riaño, 293-309. Madrid: Consejo Superior de Investigaciones Científicas.

_. 2003. "Escritura y oralidad en la Literatura Sefardí." SIGNO, Revista de Historia de la Cultura Escrita, no. 11: 37-57.

—. 2007. "El romancero sefardí, tradición e innovación." En La memoria de Sefarad. Historia y Cultura de los sefardíes. Editado por Pedro M. Piñero Ramírez, 207-232. Sevilla: Fundación Sevilla NODO-Fundación Machado.

_. 2008. "Las mujeres sefardíes del Norte de Marruecos en el ocaso de la tradición oral." En El presente. Estudios sobre la cultura sefardí. La cultura Judeo-Española del Norte de Marruecos, editado por Tamar Alexander y Yaakov Bentolila, 255-266. Beer-Sheva: Universidad Ben-Gurion del Negev-Sentro Moshe David Gaon de Kultura Djudeo-Espanyola (vol. II).

Ehrlich, Carl S. 2006. Entender el judaísmo, traducido por Maite Rodríguez Fischer. Barcelona: Blume.

Espinosa Villegas, Miguel Ángel. 1999. Judaísmo, estética y arquitectura: la sinagoga sefardí. Granada: Universidad de Granada.

Filgueira Valverde, José. 1945. "El 'planto' en la historia y en la literatura gallega." Cuadernos de Estudios Gallegos vol. IV: 511-606.

García Gómez, Jacinto L. 2007. Un banquete por Sefarad. Cocina y costumbres de los judíos españoles. Guijón: Ediciones TREA.

Giol, Carles, trad. 2016. El Zohar. El libro del Esplendor. Barcelona: Ediciones Obelisco (Colección cábala y judaísmo).

González-Blanco García, Elena. 2012. "La clerecía rabínica y su pervivencia en las coplas sefardíes. Hacia el ocaso del tetrásico castellano." En Aljamías in memoriam Álvaro Galmés de Fuentes y Iacob M. Hassán, editado por Raquel Suárez García e Ignacio Ceballos Viro, 357-376. Gijón: Ediciones Trea.

Gutkowski, Hélène. 1999. Érase una vez... Sefarad. Los sefaradíes del Mediterráneo. Su historia, su cultura, 1880-1950. Testimonios. Buenos Aires: Lumen.

Hassán, Iacob M., y Elena Romero. 1973. "Poesía luctuosa judeoespañola: Quinot paralitúrgicas." Proceedings of the World Congress of Jewish Studies vol. IV: 7-16.

Hinojosa Montalvo, José. 2000. "Los judíos en la España medieval: de la tolerancia a la expulsión." En Los marginados en el mundo medieval y moderno, coordinado por María Desamparados Martínez San Pedro, 25-41. Almería: Instituto de Estudios Almerienses.

Infante, Anelise. 2009. "España: renace negocio de las plañideras." BBC News Mundo, 3 de noviembre, 2009. https://www.bbc.com/mundo/cultura sociedad/2009/11/091103 espana_planideras_rg Revisado el 8 de febrero, 2021.

Jalfón de Bentolila, Estrella. 2011. Haketía. A Memoir of Judeo-Spanish Language and Culture in Morocco, traducido por Ron Duncan Hart y Vanessa Paloma. New Mexico: Gaon Books. 
Lotman, Iuri M. 1993. "La semiótica de la cultura y el concepto de texto." Escritos. Revista del Centro de Ciencias del Lenguaje, no. 9 (enero-diciembre): 15-20.

_.1998. La semiosfera II. Semiótica de la cultura, del texto, de la conducta y del espacio. Madrid: Ediciones Cátedra.

Molho, Michael. 1950. Usos y costumbres de los sefardíes de Salónica, traducido por Federico Pérez Castro. Madrid, Barcelona: Consejo Superior de Investigaciones Científicas.

Motis Dolader, Miguel Ángel. 2002. Hebraica Aragonalia. El legado judío de Aragón. Zaragoza: Diputación de Zaragoza-Ibercaja, Obra Social y Cultural.

Muñoz Fernández, Ángela. 2009. "Llanto, palabras y gestos. La muerte y el duelo en el mundo medieval hispánico (morfología ritual, agencias culturales y controversias)." Cuadernos de Historia de España, no. 83: 107-140.

Ortega, Manuel L. 1919. Los hebreos en Marruecos. Madrid: Ediciones Nuestra Raza.

Rouach, David. 1990. 'IMMA, ou rites, coutumes et croyances chez la femme juive d'Afrique du Nord. Paris: Maisonneuve and Larose (Collection Judaïsme en Terre d'Islam).

Ruiz Taboada, Arturo. 2014. "El cementerio judío en el contexto funerario del Toledo bajomedieval." En La judería de Toledo, un tiempo y un espacio por rehabilitar, 209-246. Cuenca: Ediciones de la Universidad de Castilla-La Mancha.

Sbarbi y Osuna, José María. 1873. Florilegio o Ramillete alfabético de refranes y modismos comparativos y ponderativos de la lengua castellana / definidos razonadamente y en estilo ameno por D. José M. Sbarbi, edición digital basada en la de Madrid, Imprenta de A. Gómez Fuentenebro. Disponible en: http://www.cervantesvirtual.com/obra-visor/florilegio-oramillete-alfabetico-de-refranes-y-modismos-comparativos-y-ponderativos-de-lalengua-castellana--0/html/ Revisado el 8 de febrero, 2021.

Vicente, Ángeles. 2011. "La presencia de la lengua española en el Norte de África y su interacción con el árabe marroquí." Revista Internacional de Lingüística Iberoamericana IX, no. 2 (18): 59-84.

Weich-Shahak, Susana. 2011. "Tradición y funcionalidad de la poesía religiosa sefardí." CALÍOPE 17, no.1: 199-215.

Zafrani, Haïm. 2001. 2000 años de vida judía en Marruecos. Bogotá: Centro de Estudios Sefardíes de Caracas, Asociación Israelita de Venezuela-L.B. Publishing C.O. de Israel. 